\title{
Are users of modern and traditional contraceptive methods in Jordan different?
}

Mona Almalik, ${ }^{1}$ Sultan Mosleh $^{2}$ and Issa Almasarweh ${ }^{3}$

${ }^{1}$ Department of Maternal and Child Health Nursing; ${ }^{2}$ Department of Adult Nursing, Faculty of Nursing, Mutah University, Alkarak, Jordan (Correspondence to: Mona M.A. Almalik: m_almalik@mutah.edu.jo). ${ }^{3}$ Department of Demography, University of Jordan, Amman, Jordan.

\begin{abstract}
Background: The level of current use of modern family planning is the most widely used indicator for evaluating the success of national family planning programmes. Recently the prevalence of traditional methods has increased in Jordan, which may lead to undesired pregnancy.
\end{abstract}

Aims: The main objective of the study was to assess the trends of modern and traditional contraceptive use in Jordan with a focus on examining the differences between the users of each method.

Methods: A secondary data analysis of the Jordan 2012 Population and Family Health Survey data was carried out. The survey used a multistage cluster random sample. Bivariate analysis was conducted to identify the difference between modern and traditional contraceptive users. A logistic regression model was used to study significant covariates.

Results: Among 10801 currently married women aged 15-49 years surveyed, 38.8\% were not using any contraceptive method, $18.9 \%$ used traditional methods, and $42.3 \%$ relied on modern contraceptive methods. Logistic regression analysis revealed 4 significant predictors of using modern contraceptive methods: location in Central Region, residence in urban areas, age and parity.

Conclusion: Women, particularly those resident in the southern region, should be encouraged to use modern contraceptive methods and this may be achieved by empowering them with more information about sources of these methods that are available to them. Family planning interventions should focus on younger and high parity women as they were more likely to use traditional methods.

Keywords: Jordan, family planning, modern/traditional contraception

Citation: Almalik M; Mosleh S; Almasarweh I. Are users of modern and traditional contraceptive methods in Jordan different? East Mediterr Health J. 2018;24(4):377-384. https://doi.org/10.26719/2018.24.4.377

Received: 09/11/15; accepted: 05/04/17

Copyright (C) World Health Organization (WHO) 2018. Some rights reserved. This work is available under the CC BY-NC-SA 3.0 IGO license (https:// creativecommons.org/licenses/by-nc-sa/3.o/igo).

\section{Introduction}

Contraceptive methods are often classified as either modern [barrier methods such as male and female condoms, diaphragm, cervical cap and sponge; hormonal contraceptives that include oral, injectable, transdermal, vaginal ring, and implants; intrauterine device (IUD)] or traditional [rhythm method (periodic abstinence), withdrawal (coitus interruptus), fertility awareness-based methods, the lactational amenorrhoea method and folk methods]. Emergency contraception and permanent methods including female sterilization and vasectomy for men (1). Contraceptive use is generally estimated from household survey data. The most common survey worldwide is the Demographic and Health Survey, in which data have been collected through nationally representative cross-sectional surveys in 90 developing countries. The survey is usually conducted at 5-year intervals and has been carried out 6 times in Jordan.

Use of a contraceptive method helps couples plan their family by avoiding undesired pregnancies and consequently serving their intention to stop and/or postpone childbearing through choice. Choice of which contraceptive method to use is affected by factors such as the couple's desires and knowledge about methods, access to and availability of methods, providers' attitudes and biases, quality of care and counselling, and service cost (2-5).

Family planning programmes usually promote the use of modern methods rather than traditional methods as the latter have a higher failure rate. However, it is only when the use of modern methods is declining and the use of traditional methods is increasing that family planning managers become concerned about such changes and start to investigate whether the gain in traditional methods has come at the expense of modern methods.

In Jordan, the overall contraceptive prevalence rate has increased markedly over the past 2 decades, from $40 \%$ in 1990 to $61 \%$ in 2012. However, the reliance on modern methods has levelled off at $42 \%$ in the last decade (6), which is not in line with Jordan's family planning programme objective of achieving $80 \%$ of currently married women (15-49 years) using modern contraceptives (6). The 12-month contraceptive discontinuation rate remained high for all methods (48\%) (7). Furthermore, the proportion of women whose last birth was unplanned was $25 \%$, accounting for 45000 births annually (7). This 
can have tremendous adverse effects on couples and on society $(8,9)$.

Although there is no ideal method mix for a country, there is a concern when contraceptive users rely mainly on a single provider-based method (IUD) and on traditional methods (10). The findings of 4 consecutive Jordan Population and Family Health Surveys (7) carried out in the last decade show that the use of modern methods is levelling off while the use of traditional methods has been increasing (from $15 \%$ to $19 \%$ ) (10). Furthermore, Jordan has an unbalanced or skewed method mix compared with some other countries in the Region, with a dominance of IUD, which together with traditional methods accounts for two-thirds of contraceptive use. Among 109 developing countries, Jordan is among the 20 countries that have the highest prevalence of traditional methods, accounting for $30 \%$ or more of all methods used in the country (10).

Investigating the major contributing factors associated with modern methods can better inform family planning programmes. Hence, the main research question is: are women who are using modern methods in Jordan different from those who are using traditional contraceptive methods? This question is pertinent because the effectiveness of the method used has been found to vary by users' background characteristics as well as by type of method (9).

Limited research has been conducted in Jordan to explore factors that influence the selection of family planning methods. Therefore, this study aimed to assess the trends of modern and traditional contraceptive use in Jordan, identify the independent predictors of the use of contraceptive methods and examine the differences between users of modern and traditional methods.

\section{Methodology}

\section{Data source}

This study is a secondary data analysis of the 2012 Jordan Population and Family Health Survey (7). The survey sample is a multistage cluster random sample representative of the entire population of Jordan as well as the subnational strata. The survey provides cross-sectional data through a series of questions collecting data on reproductive history as well as most recent pregnancy outcomes for 10801 currently married women of reproductive age (15-49 years). Since the survey provides data at the national and subnational levels, it allows for the analysis of regional and socioeconomic differentials in family planning practices. The subnational and other subgroups include rural/urban, badia/refugee camps (badia is defined as the area that extends from the east across to where the western mountains border the Jordan Valley), governorates, educational attainment and wealth index. The correlates include woman's age, pregnancy order, parity, consanguinity, body mass index and birth intervals.

\section{Ethical considerations}

This study did not require the approval of an institutional review board because it used unidentified respondents' information from an official data source which is provided in the public domain by the Jordan Department of Statistics (7). The data did not include personal identification features, and the statistician did not have access to any personal identification of respondents, thus the study was deemed ethically safe.

\section{Data analysis procedures}

Data analysis was conducted using SPSS, version 21. Bivariate analysis (chi-squared test and t-test) was carried out to test the difference between modern and traditional contraceptive use based on sociodemographic variables. Since the dependent variable is categorical (use of modern vs traditional contraceptive methods), a logistic regression model was used to determine the difference in adjusted odds ratios between traditional and modern contraceptive users. The odds ratio (OR) and 95\% confidence interval (CI) were calculated and $\mathrm{P} \leq 0.05$ was considered statistically significant.

\section{Results}

Information was collected regarding 10801 currently married women aged 15-49 years, among whom 38.8\% were not using any contraceptive method and $61.2 \%$ were using a method at the time of interview for the Jordan Population and Family Health Survey (7), 18.9\% were using traditional methods and $42.3 \%$ were relying on modern methods. Among women who were not using any method, $65.0 \%$ were not educated, $72.5 \%$ were in the age group 15-19 years and 52.0\% lived in rural areas.

Among women who were using contraception, the IUD was the most used method (21.0\%) among modern methods, and pills and male condoms were joint second, $8 \%$ for each. Withdrawal and the rhythm method were the most commonly used among the traditional methods (14.3\% and 3.5\%, respectively).

Overall, the use of any method among currently married women increased from $40 \%$ in 1990 to $61 \%$ in 2012. There was considerable change in the use of specific contraceptive methods in the same period. Use of the IUD increased among currently married women from $15 \%$ in 1990 to $21 \%$ in 2012 . In addition, the use of the male condom increased from less than $1 \%$ to $8 \%$. The use of withdrawal also increased, from 4\% in 1990 to $14 \%$ in 2012. The discontinuation rate of contraceptive use increased over the same period, accompanied by a decline in the use of long-term methods, such as female sterilization and IUD in favour of condom and withdrawal.

The use of contraceptive methods among currently married women varied with age. The highest proportion (51\%) of women who were using modern methods was in the age group 35-44 years, and the lowest (21.8\%) was among the age group 15-19 years. The proportion of currently married women who were using traditional methods ranged between $5.7 \%$ and $20.2 \%$, highest in the age groups 25-29 years and 35-39 years. The lowest proportion using traditional methods was among the age group 15-19 years (5.7\%). Older women depended more 


\begin{tabular}{|c|c|c|c|}
\hline \multirow[t]{2}{*}{ Characteristic } & $\begin{array}{l}\text { Traditional methods } \\
(n=2037)\end{array}$ & $\begin{array}{l}\text { Modern methods } \\
\quad(n=4579)\end{array}$ & \multirow[t]{2}{*}{ P-value } \\
\hline & Mean (SD) & Mean (SD) & \\
\hline Wealth index & $3.06(1.36)$ & $3.05(1.37)$ & $0.764^{\mathrm{a}}$ \\
\hline Parity & $3.86(2.08)$ & $4.35(2.09)$ & $0.001^{\mathrm{a}}$ \\
\hline \multirow[t]{2}{*}{ Ideal no. of children } & $3.68(1.25)$ & $3.66(1.30)$ & \multirow[t]{2}{*}{$0.678^{\mathrm{a}}$} \\
\hline & $\%$ & $\%$ & \\
\hline \multicolumn{4}{|c|}{ Woman's age (years) $(n=6616)$} \\
\hline $15-19$ & 0.7 & 1.3 & \multirow{7}{*}{$0.05^{\mathrm{b}}$} \\
\hline $20-24$ & 9.7 & 7.7 & \\
\hline $25-29$ & 19.9 & 15.9 & \\
\hline $30-34$ & 19.4 & 20.7 & \\
\hline $35-39$ & 19.0 & 22.4 & \\
\hline $40-44$ & 18.9 & 21.7 & \\
\hline $45-49$ & 12.4 & 10.3 & \\
\hline \multicolumn{4}{|l|}{ Region $(n=6616)$} \\
\hline Centre & 31.4 & 63.9 & \multirow{3}{*}{$0.038^{\mathrm{b}}$} \\
\hline North & 24.4 & 27.5 & \\
\hline South & 44.2 & 8.6 & \\
\hline \multicolumn{4}{|l|}{ Residence $(n=6615)$} \\
\hline Urban & 40.8 & 84.0 & \multirow{2}{*}{$0.002^{\mathrm{b}}$} \\
\hline Rural & 60.2 & 16.0 & \\
\hline \multicolumn{4}{|c|}{ Woman's education level $(n=6616)$} \\
\hline None & 7.6 & 1.6 & \multirow{4}{*}{$0.033^{b}$} \\
\hline Primary & 37.5 & 6.4 & \\
\hline Secondary & 26.5 & $57 \cdot 5$ & \\
\hline Higher & 28.4 & 34.5 & \\
\hline \multicolumn{4}{|c|}{ Husband's desire for children $(n=6370)$} \\
\hline Both want same & 54.4 & 51.4 & \multirow{4}{*}{$0.002^{\mathrm{b}}$} \\
\hline Husband wants more & 34.2 & 11.5 & \\
\hline Husband wants fewer & 8.2 & 33.7 & \\
\hline Don't know & 3.2 & 3.3 & \\
\hline \multicolumn{4}{|l|}{ Badia $(n=6616)$} \\
\hline Inside badia & 72.1 & 44.7 & \multirow{2}{*}{$0.040^{b}$} \\
\hline Outside badia & 27.9 & $55 \cdot 3$ & \\
\hline \multicolumn{4}{|l|}{ Camps $(n=6615)$} \\
\hline Inside camps & 43.6 & 63.3 & \multirow{2}{*}{$0.035^{\mathrm{b}}$} \\
\hline Outside camps & 66.4 & 36.4 & \\
\hline
\end{tabular}

andependent t-test.

${ }^{b}$ Chi-squared test.

$S D=$ standard deviation.

on long-acting and permanent methods such as IUD and female sterilization, while younger women relied more on temporary modern methods such as pills and the male condom.

Bivariate analysis showed no significant difference between the 2 groups in relation to the wealth index (Table 1). However, women who were currently using modern methods had significantly more children compared with women using traditional methods. In addition, the use of modern methods of contraception was significantly more likely in the age group 35-39 years compared with women in the age group 25-29 years. Women residing in urban areas, the central region, camps, outside the badia, and having secondary or higher education were significantly more likely to use modern methods compared with women living in rural areas, 
the southern region, badia, outside camps and having no education. The use of modern contraceptive methods was significantly more likely among women whose husbands had a desire for fewer children (33.7\% vs $8.2 \%$ ). On the other hand, the use of traditional methods was significantly more likely among women whose husbands had decided to have more children (34.2\% vs 11.5\%) (Table 1). No other significant relationship was found between any of the respondents' characteristics and using either modern or traditional contraceptive methods.

Taking into account the influence of all other covariates simultaneously, multiple logistic regression was conducted to identify the independent predictors for use of contraceptive methods. Only those variables that were statistically significant in the bivariate analysis were considered for entry into the logistic models. These included woman's age, parity, husband's desire for children, woman's education, region (location), and urban/rural residence (Table 2).

The results revealed 4 significant predictors for use of modern contraceptive methods: location in the central region (OR 1.23; 95\% CI: 1.04-1.46), urban area of residence (OR 1.20; 95\% CI: 1.01-1.42), mother's age (OR 0.97; 95\% CI: $0.95-0.99$ ) and parity (OR 1.16; 95\% CI: 1.08-1.25). Women living in the central region and in urban areas were more likely to use modern contraceptive methods compared with women living in rural areas and in the southern or northern regions. In addition, the lower a woman's age, the higher the chance of using a modern method. Finally, as number of children increased, women were more likely to rely on modern contraceptive methods than on traditional ones (Table 2).

\section{Discussion}

We investigated key factors associated with type of contraceptive methods used by currently married Jordanian women. The modern methods most frequently distributed by family planning services are IUD, male condom, and hormonal contraceptives (oral, injectable, and implanted). However, the results of the latest Jordan Population and Family Health Survey indicated that IUD was the most used modern method, followed by pills and male condom (7). This may be explained by the feasibility of applying these methods by users (pills and condom). Cultural preferences and the availability of IUDs could explain their high prevalence compared to other modern methods such as implantable hormonal methods.

The results indicated that using modern or traditional methods differed according to women's characteristics. The use of modern methods of contraception was predicted by the increase in the number of children ever born. Similar results have been found in many developing countries such as Bangladesh, Pakistan and Tanzania (3,11,12) and in 1 Arab country, Oman (13), where modern methods were more predominant as the number of children increased.

Multivariate analysis showed that the chance of using modern methods decreased with increased age of the woman. This may be explained by the following possible reasons: firstly, younger women are usually more open

\begin{tabular}{|c|c|c|c|c|c|c|}
\hline Variable & B & $\begin{array}{l}\text { Standard } \\
\text { error }\end{array}$ & t-value & P-value & Odds ratio & $\begin{array}{l}\text { 95\% confidence } \\
\text { interval }\end{array}$ \\
\hline \multicolumn{7}{|c|}{ Husband's desire for children } \\
\hline Both want same & 0.006 & 0.225 & 0.026 & 0.979 & 1.006 & $0.647-1.565$ \\
\hline Husband wants more & 0.129 & 0.247 & 0.521 & 0.602 & 1.137 & $0.700-1.848$ \\
\hline Husband wants fewer & -0.043 & 0.250 & -0.171 & 0.864 & 0.958 & $0.587-1.565$ \\
\hline Do not know (ref) & & & & & 1.000 & \\
\hline \multicolumn{7}{|l|}{ Woman's education } \\
\hline None & -0.230 & 0.337 & -0.683 & 0.495 & 0.794 & $0.410-1.540$ \\
\hline Primary & -0.274 & 0.245 & -1.116 & 0.265 & 0.761 & $0.470-1.231$ \\
\hline Secondary & 0.081 & 0.118 & 0.683 & 0.495 & 1.084 & $0.859-1.367$ \\
\hline Higher(ref) & & & & & 1.000 & \\
\hline \multicolumn{7}{|l|}{ Region } \\
\hline Central & 0.211 & 0.087 & 2.421 & 0.016 & 1.235 & $1.041-1.465$ \\
\hline North & 0.151 & 0.087 & 1.742 & 0.082 & 1.163 & $0.981-1.378$ \\
\hline South (ref) & & & & & 1.000 & \\
\hline \multicolumn{7}{|l|}{ Residence } \\
\hline Urban & 0.185 & 0.087 & 2.128 & 0.034 & 1.203 & $1.014-1.427$ \\
\hline Rural (ref) & & & & & 1.000 & \\
\hline Mother's current age & 0.027 & 0.010 & 2.714 & 0.007 & 0.974 & $0.955-0.993$ \\
\hline Parity & 0.152 & 0.038 & 3.997 & 0.000 & 1.164 & $1.080-1.254$ \\
\hline
\end{tabular}


to adopting modern technology and are often less bound to cultural beliefs than older women; younger women are generally better educated than older women so they would be more prone to accepting and using modern contraception; and as women realize they are reaching their desired family size at younger ages, they may decide to have no more children. Women's awareness regarding the decline in their fertility with increased age could be another reason for reducing the chance of using modern contraceptive methods with increased age. Additionally, increasing age is associated with a decrease in women's desire for sexual activity thus decreasing the chance of using modern methods (14). This is similar to findings of previous studies in Ethiopia and Nigeria (15-17), which found that the use of modern methods was greater in younger women. The Ethiopian study attributed the results to rigorous family planning programmes that targeted this age group (17). Taken together with the findings of the present study, this suggests the importance of directing family planning policies to target both young and older Jordanian women to motivate them to use more modern contraception.

We found that women who live in urban areas significantly used more modern methods compared with those in rural areas. We also found that women from the central region were more likely to use modern methods compared to those from the southern region. This could be related to better implementation of family planning services in terms of educational materials and number of centres in urban areas. Similarly, a number of previous studies in other countries have found that modern family planning methods were more likely to be adopted in urban areas $(18,19)$. The Ministry of Health in Jordan has implemented rigorous family planning programmes over the past 2 decades to reduce the fertility rate, which has fallen from 5.6 in 1990 to 3.5 in 2012 (7), and to make those programmes accessible in rural areas. The difference between regions in the type of contraceptive methods used could be explained by the characteristics of women in the southern region, as reported in the latest (2012) Demographic and Health Survey (7), who had the lowest level of current use of family planning, and the least contact with health care providers. In addition, traditional factors and community influence towards having more children, particularly sons, could explain the differences in use of modern contraceptive methods between regions $(4,13,18)$. This explanation could be supported by the differences in total fertility rate among areas and regions: total fertility rate in rural areas is higher compared to urban areas (3.9 vs 3.4, respectively) and total fertility rate is higher in the southern region than in the central region (3.7 vs 3.4, respectively) (7). This finding should incentivize policy-makers to establish and implement effective strategies in rural areas and to encourage women to visit health centres and use modern contraceptive methods.

Bivariate analysis showed that secondary or higher level of education was associated with using modern contraceptive methods, but this no longer held after controlling for other factors. This might be explained by the greater number of educational materials and centres available for women in urban areas, which may make the effect of the women's education minimal or disappear. Previous Jordanian studies have found that education level and economic status play an essential role in influencing the use of contraceptive methods (20-23), but these studies did not examine the effect of the woman's education level on selecting the type of contraceptive method. Other studies have also found the association still holding between education and use of family planning methods. For example, a Turkish health survey, a recent Omani study and 3 Ethiopian health surveys found that highly educated women significantly chose modern methods $(14,17,18,24)$.

Previous studies have highlighted the importance of women's concern for well-being and husbands' beliefs about contraceptive methods as important associated factors for selecting appropriate methods $(22,25)$. The univariate analysis in this study found that husbands' desire for children was a factor in the selection of contraceptive method. This is consistent with Jordanian culture, a male-dominated culture, in which the wife relinquishes reproductive decisions to her husband $(26,27)$. A husband's decision on choice of contraceptive method may be influenced by the number and sex of children; a Palestinian study found that husbands' desire was to have 2 sons, while in Jordan and Egypt the desire was for 3 sons $(26,28,29)$. On the other hand, we found that husbands' desire for more children did not hold as a predictor for selecting contraceptive method after controlling for other factors. A recent Ethiopian study found that the desire for more children was the main reason for not using modern contraceptive methods, but did not compare the use of traditional and modern methods (3).

This study was based on a national survey; therefore the sample is highly representative of currently married Jordanian women. Also, to our knowledge, this is the first study to highlight the contributing factors for the use of traditional contraceptive methods, which provides a foundation for future evidence-based interventions to reduce the use of traditional methods and increase the use of modern methods. As this study is a secondary analysis of a survey, the potential for discovering factors that may influence a couple's decision to use contraceptive methods for spacing or limiting births was limited. Other potential factors that were excluded include women's perceptions and religion, couples' knowledge about the advantages and disadvantages of the various contraceptive methods, access to contraceptive services in rural versus urban areas, providers' biases towards certain methods, and couples' fears and rumours regarding certain methods.

\section{Conclusion}

The high percentage of Jordanian women who are not currently using any modern contraceptive methods $(58 \%)$ and the high level of reliance on traditional methods (31\% of all users) raise concern about unfavourable birth in- 
tervals, maternal and child health, and couples' fertility desires with respect to unintended pregnancies and socioeconomic consequences.

Our study sheds light on important factors associated with the use of modern and traditional methods among a sample of Jordanian currently married women. Findings of this study are important to health care providers and health/family planning policy-makers as they need to establish and implement programmes to increase women's awareness of the importance of using modern methods in rural areas and in the southern region, which have high fertility rates. Researchers and policymakers need to explore possible cultural and traditional issues that contribute to couples' decisions about type of contraceptive method use, such as the number of children and number of sons to have.

Family planning programme managers in Jordan need to consider necessary changes in their operational policies based on the findings of the multivariate analysis.
Efforts to shift users of traditional methods to modern contraceptive methods, and to increase the prevalence of modern contraceptives need to target high parity women, young women under 25 years and older women over 45 years, who may have misinformation and fears about modern methods. This can be achieved by developing and implementing educational programmes early at school age and enhancing women's attendance at antenatal and postnatal clinics to receive effective family planning counselling. Family planning programmes in the southern region can focus more on health care providers. Women in that region may need greater motivation and encouragement to use modern contraceptive methods; this could be achieved by increasing their knowledge about modern methods through individual educational sessions and educational materials.

Funding: None.

Competing interests: None declared.

\section{Les utilisatrices de méthodes contraceptives traditionnelles et modernes sont-elles differentes en Jordanie? RÉSUMÉ}

Contexte : Le niveau actuel de recours à la planification familiale moderne est l'indicateur le plus largement utilisé pour évaluer le succès des programmes nationaux de planification familiale. Récemment, la prévalence des méthodes traditionnelles a connu une augmentation en Jordanie, ce qui peut entraîner des grossesses non désirées.

Objectifs: La présente étude avait pour objectif principal d'évaluer les tendances de l'utilisation de méthodes contraceptives modernes et traditionnelles en Jordanie, en se concentrant sur l'examen des différences entre les utilisatrices de chaque méthode.

Méthodes : Une analyse des données secondaires de l'Enquête 2012 sur la population et la santé familiale en Jordanie a été menée. L'étude a utilisé la méthode d'échantillonnage aléatoire en grappes à plusieurs degrés. Une analyse bivariée a été conduite afin d'identifier les différences entre les utilisatrices de méthodes contraceptives modernes et traditionnelles. Un modèle de régression logistique a été utilisé pour étudier les covariables significatives.

Résultats: Parmi 10801 femmes mariées âgées de 15 à 49 ans interrogées, 38,8\% n'utilisaient aucune méthode contraceptive, 18,9\% avaient recours à des méthodes traditionnelles et 42,3\% utilisaient des méthodes contraceptives modernes. L'analyse de régression logistique a révélé quatre facteurs prédictifs significatifs de l'utilisation de méthodes contraceptives modernes : le fait de vivre dans la Région centrale, d'habiter en zones urbaines, l'âge et la parité.

Conclusion : Les femmes, et particulièrement celles vivant dans la région du sud, devraient être encouragées à utiliser des méthodes contraceptives modernes, ce qui peut être réalisé en leur fournissant davantage d'informations sur les méthodes à leur disposition et en contribuant ainsi à leur autonomie. Les interventions de planification familiale devraient se concentrer sur les jeunes femmes et les femmes à parité élevée, celles-ci étant plus susceptibles de recourir à des méthodes traditionnelles.

$$
\begin{aligned}
& \text { هل تختلف مستخدمات وسائل منع الحمل الحلديثة والتقليدية في الأردن؟ } \\
& \text { منى المالك، سلطان مصلح، عيسى المصاروة } \\
& \text { الخالاصة }
\end{aligned}
$$

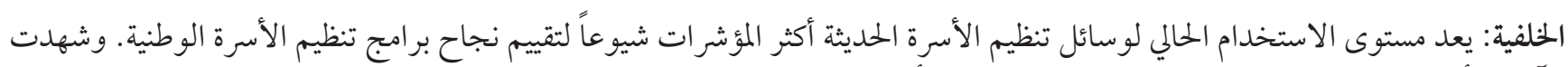

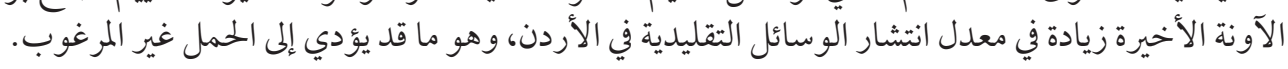

$$
\begin{aligned}
& \text { الأهداف: تمثل الهدف الأساسي لهذه الدراسة في تقييم اتجاهات استخدام وسائل منع الحمل الحديثة والتقليدية في الأردن مع التركيز على دراسة } \\
& \text { الاختلافات بين مستخدمي كل الافيلة وسيلة. }
\end{aligned}
$$

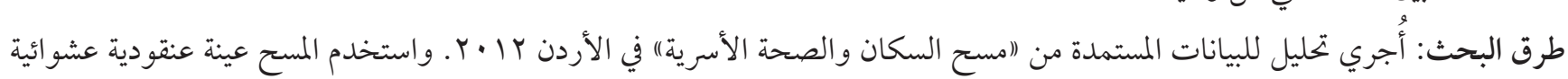




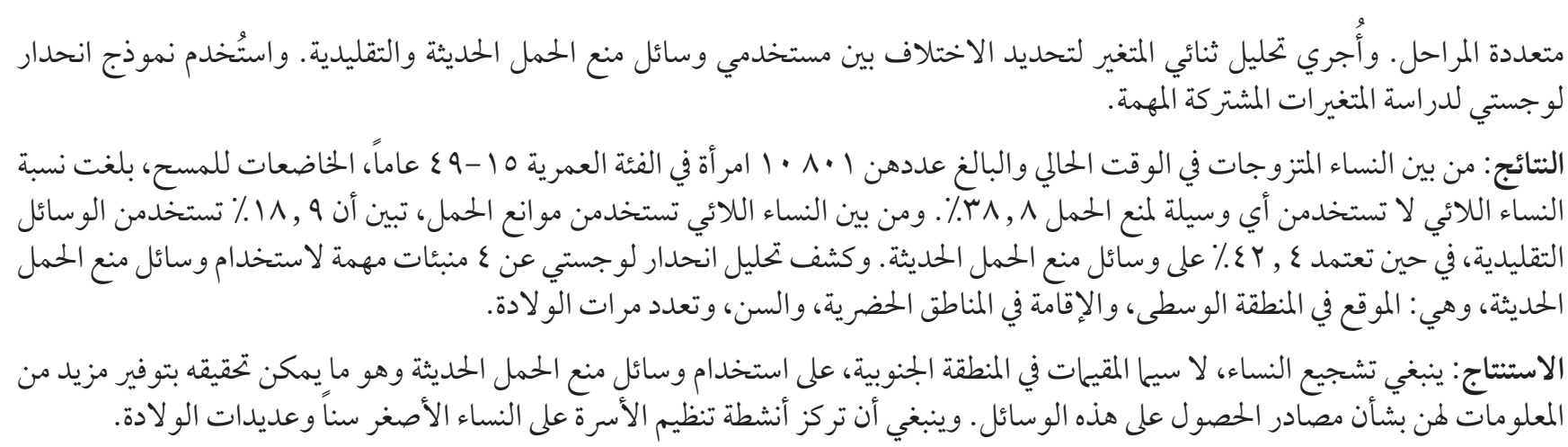

\section{References}

1. Ricci SS. Essentials of maternity, newborn, and women's health nursing. Philadelphia: Lippincott Williams \& Wilkins; 2013.

2. Sharma S, Pasha A. Degree of pervasiveness of traditional contraception in Indian women. Shodh Prerak. 2011;1(2):158.

3. Mohammed A, Woldeyohannes D, Feleke A, Megabiaw B. Determinants of modern contraceptive utilization among married women of reproductive age group in North Shoa Zone, Amhara Region, Ethiopia. Reprod Health. 2014;11(1):13. PMID:24490810

4. Hettiarachchi J, Gunawardena NS. Factors related to choice of modern vs traditional contraceptives among women in rural Sri Lanka. Sri Lanka J Obstet Gyn. 2011;33(1):20-5.

5. Agha S, Williams E. Does the antenatal care visit represent a missed opportunity for increasing contraceptive use in Pakistan? An analysis of household survey data from Sindh province. Health Policy Plan. 2016:31(3):325-31. PMID:26208505

6. Health policy initiative. The cost of family planning in Jordan. Washington, DC: USAID; 2010.

7. Jordan Population and Family Health Survey 2012. Amman, Jordan: Department of Statistics. 2012.

8. Logan C, Holcombe E, Manlove J, Ryan S. The consequences of unintended childbearing. Washington, DC: Child Trends and National Campaign to Prevent Teen Pregnancy; 2007:142-51.

9. Mackenzie H, Drahota A, Pallikadavath S, Stones W, Dean T, Fogg C, et al. What is the impact of contraceptive methods and mixes of contraceptive methods on contraceptive prevalence, unmet need for family planning, and unwanted and unintended pregnancies? London: EPPI-Centre, Social Science Research Unit, Institute of Education, University of London; 2013.

10. Bertrand JT, Sullivan TM, Knowles EA, Zeeshan MF, Shelton JD. Contraceptive method skew and shifts in method mix in lowand middle-income countries. Int Perspect Sex Reprod Health. 2014;40(3):144-53. PMID:25271650

11. Kamal SM, Islam MA. Contraceptive use: socioeconomic correlates and method choices in rural Bangladesh. Asia Pac J Public Health. 2010;22(4):436-50. PMID:20659903

12. Lwelamira J, Mnyamagola G, Msaki M. Knowledge, attitude and practice (KAP) towards modern contraceptives among married women of reproductive age in Mpwapwa District, Central Tanzania. Current Res J Soc Sci. 2009; 4:235-45.

13. Al-balushi MS, Ahmed MS, Mazharul Islam M, Rahaman Khan MH. Contraceptive method choices among women in Oman: a multilevel analysis. J Data Science. 2016;14(1):117-32.

14. Taylor A, Gosney MA. Sexuality in older age: essential considerations for healthcare professionals. Age Ageing. 2011;40(5):538-43. PMID:21778176

15. Gordon C, Sabates R, Bond R, Wubshet T. Women's education and modern contraceptive use in Ethiopia. Int J Education. 2011;3(1):1.

16. Ogbe COA, Okezie C. Socio-economic determinants of contraceptive use among rural women in Ikwuano Local Government Area of Abia State, Nigeria. Int NGO J. 2010;5(4):74-7.

17. Worku AG, Tessema GA, Zeleke AA. Trends of modern contraceptive use among young married women based on the 2000 , 2005, and 2011 Ethiopian demographic and health surveys: a multivariate decomposition analysis. PloS One. 2015;10(1):e0116525. PMID:25635389

18. Bogale B, Wondafrash M, Tilahun T, Girma E. Married women's decision making power on modern contraceptive use in urban and rural southern Ethiopia. BMC Public Health. 2011;11(1):1. PMID:21595897

19. Ram F, Shekhar C, Chowdhury B. Use of traditional contraceptive methods in India \& its socio-demographic determinants. Indian J Med Res. 2014;140(Suppl. 1):S17-28. PMID:25673538

20. Gharaibeh MK, Oweis A, Shakhatreh FM, Froelicher ES. Factors associated with contraceptive use among Jordanian Muslim women: implications for health and social policy. J Int Women's Studies. 2011;12(3):168.

21. Hasna F. Islam, social traditions and family planning. Soc Policy Admin. 2003;37(2):181-97.

22. Albsoul-Younes A, Saleh F, El-Khateeb W. Perception of efficacy and safety as determinants for use and discontinuation of birth control methods in Muslim Jordanian women. Eur J Contracept Reprod Health Care. 2003;8(3):156-61. PMID:14667327 
23. Sueyoshi S, Ohtsuka R. Significant effects of Fatwa-based perception on contraceptive practice among Muslim women in south Jordan under the early stage of fertility transition. Biodemography Social Biol. 2010;56(1):67-79.

24. Cindoglu D, Sirkeci I, Sirkeci RF. Determinants of choosing withdrawal over modern contraceptive methods in Turkey. Eur J Contracept Reprod Health Care. 2008;13(4):412-21. PMID:19117258

25. Libbus K, Kridli S. Contraceptive decision making in a sample of Jordanian Muslim women: delineating salient beliefs. Health Care Women Int. 1997;18(1):85-94. PMID:9119785

26. Kridli S, Libbus K. Contraception in Jordan: a cultural and religious perspective. Int Nurs Rev. 2001;48(3):144-51. PMID:11558689

27. Petro-Nustas W, Al-Qutob Rd. Jordanian men's attitudes and views of birth-spacing and contraceptive use (a qualitative approach). Health Care Women Int. 2002;23(6-7):516-29.

28. Yount KM, Langsten R, Hill K. The effect of gender preference on contraceptive use and fertility in rural Egypt. Stud Fam Plann. 2000;31(4):290-300. PMID:11198066

29. Memmi S, Du Loû AD. Gender relations and contraceptive practices of Palestinian couples. Population. 2015;70(2):273-308. 